\title{
Microbiology of vaginal discharge in Nairobi, Kenya
}

\author{
N B MIRZA,* H NSANZE,* L J D'COSTA,† AND P PIOT
}

From the *Department of Medical Microbiology, University of Nairobi; + Nairobi City Council Special Treatment Centre, Nairobi, Kenya; and the $¥ D$ Department of Microbiology, Institute of Tropical Medicine, Antwerp, Belgium

SUMMARY Among women attending a sexually transmitted disease (STD) clinic in Nairobi with vaginal discharge, Neisseria gonorrhoeae and Chlamydia trachomatis were isolated from the cervix in $32(26 \%)$ of 122 and four $(7 \%)$ of 58 women respectively. Infection with Trichomonas vaginalis, Candida albicans, Gardnerella vaginalis, and Mycoplasma spp were diagnosed in 42 of $\stackrel{0}{=}$ $122(34 \%)$, 26 of $110(24 \%), 75$ of $100(75 \%)$, and 42 of $89(47 \%)$ women respectively. Mixed $\circlearrowleft$ infections with at least two pathogens were found in $23(26 \%)$ of 89 women examined for all microorganisms. Infection with $N$ gonorrhoeae was significantly associated with abdominal pain.

\section{Introduction}

Vaginal discharge, the major sign of vaginitis, is the most common presenting feature in women attending sexually transmitted diseases (STD) clinics. Reliable data on the occurrence and aetiology of vaginitis in developing countries are virtually non-existent. Information on female genital infections in Africa relates to women who attend antenatal and family planning clinics $^{1-4}$ and to prostitutes. ${ }^{5}$ Data on infection with Gardnerella vaginalis and Chlamydia trachomatis and Mycoplasma hominis, two potential causes of pelvic inflammatory disease (PID), were not available.

Complications of genital tract infections such as pelvic inflammatory disease and its sequelae are common in Kenya..$^{6-8}$ For rational management and prevention of these complications, it is necessary to know which pathogens are involved in uncomplicated infections. This study was therefore carried out to determine the incidence of infection with Neisseria gonorrhoeae, $C$ trachomatis, Trichomonas vaginalis, Candida albicans, $G$ vaginalis, and Mycoplasma spp in women with vaginal discharge attending a clinic for sexually transmitted diseases in Nairobi, Kenya.

\section{Patients and methods}

One hundred and twenty-two consecutive unselected patients who attended Nairobi city council's STD clinic during two weeks in January 1982 complaining

Address for reprints: Dr N B Mirza, Department of Medical Microbiology, University of Nairobi, P O Box 30588, Nairobi, Kenya

Accepted for publication 14 December 1982 of vaginal discharge were studied. A gynaecological history including questions on the character of the $\bar{c}$ discharge, abdominal pain, and dysuria was taken.

Specimens for culture of $N$ gonorrhoeae and $C \vec{\oplus}$ trachomatis were collected from the cervical os and $\underset{\omega}{\infty}$ from the posterior fornix (for other microorganisms). All culture media were inoculated 0 immediately in the clinic. Specimens for chlamydial culture were placed into sucrose phosphate buffer transport medium. For the detection of clue cells a saline mount of vaginal material from 100 women $\cong$ was made. Direct microscopy for infection with $T \overrightarrow{\overrightarrow{0}}$ vaginalis was performed in all 122 patients; this 3 protozoon was identified as a mobile flagellate. Secretions from each woman were cultured for $N$ 우 gonorrhoeae on Thayer-Martin medium (122 孚 patients), for $C$ albicans on Sabouraud's dextrose agar (110 patients), for $G$ vaginalis on human bilayer 3 . medium (100 patients), ${ }^{9}$ for $C$ trachomatis on cycloheximide treated McCoy cells (58 patients), ${ }^{10}$ and on mycoplasma medium (89 patients). ${ }^{11}$ Plates for $N_{\odot}$ gonorrhoeae and $G$ vaginalis and mycoplasmas were incubated in $5 \% \mathrm{CO}_{2}$ in a candle extinction jar for up to 48 hours. Suspected colonies of $N$ gonorrhoeae were identified by oxidase reaction and Gram stain $N$ and tested for $\beta$-lactamase production by the $N$ nitrocefin method. ${ }^{12}$ Candida spp were identified as $N$ $C$ albicans by germ tube formation. $G$ vaginalis was $\sigma$ identified as described. ${ }^{13}$ Mycoplasma colonies were identified by their typical "fried egg" appearance under the microscope on application of Diene's stain to the colonies; they were not identified to species ? level.

STATISTICAL ANALYSIS
For statistical analysis, the $\chi^{2}$ test with Yates's $\frac{\varrho}{\square}$ correction and Fisher's exact test were used. 


\section{Results}

Most women examined were between 20 and 29 years old with a mean age of 23 years. $N$ gonorrhoeae was isolated from 32 of the 122 patients and occurred more frequently (13 of 98 women) in women who were under 20 years of age (table I). This difference was not, however, significant $\left(\chi^{2}=1 \cdot 26\right)$. $N$ gonorrhoeae was not found in womer of 30 years or older $(p=0.015$, Fisher's exact test). None of the $N$ gonorrhoeae isolates produced $\beta$-lactamase. There was no significant difference in the age specific isolation rate for the other microorganisms.

The relationship of abdominal pain to the genera and species isolated is shown in table II. $N$ gonorrhoeae was isolated in $41 \%$ of women with abdominal pain compared with $19 \%$ of those without $\left(\chi^{2}=5.41, p=0.02\right)$. Chlamydiae were also more frequently isolated in patients with abdominal pain, but the numbers were too small for statistical analysis. The reverse occurred for genital mycoplasmas, as they were isolated significantly more frequently (in 31 of 47 women) in patients who did not complain of abdominal pain. Cervical erosion and dysuria were found in 71 and 21 women respectively with vaginal discharge. Either alone or together these conditions were not significantly associated with any particular organism. Other findings included scars of healed genital ulcers in eight women, one of whom had a bubo as well. One patient had a Bartholin's abscess, one vulval condylomata, and one labial ulceration.

Clue cells were found in 70 of the 100 women examined and were always associated with isolation of $G$ vaginalis. This organism was isolated from 25 $(83 \%)$ of 30 patients in whom no other pathogen was identified compared with $35(70 \%)$ of 50 of the other women (difference not significant). There was an inverse relationship between $G$ vaginalis and $C$ albicans; when the second was isolated only $50 \%$ of the patients also harboured $G$ vaginalis compared with $80 \%$ of women who did not have candidosis ( $p=0 \cdot 04$, Fisher's exact test). Mixed infections with at least two pathogens, but not $G$ vaginalis, were found in $23(26 \%)$ of 89 women who were examined for all microorganisms.
TABLE II Micro-organisms isolated from patients with vaginal discharge with or without abdominal pain. (Figures are number of positive cultures/number of patients tested with percentage of positives in parentheses)

\begin{tabular}{lll}
\hline & \multicolumn{2}{l}{ Abdominal pain } \\
\cline { 2 - 3 } Organism isolated & Present & Absent \\
\hline$N$ gonorrhoeae & $16 / 39(41)$ & $16 / 83(19)^{*}$ \\
$T$ vaginalis & $13 / 39(33)$ & $29 / 83(35)$ \\
$C$ albicans & $7 / 36(19)$ & $19 / 74(26)$ \\
$G$ vaginalis & $27 / 35(79)$ & $48 / 65(74)$ \\
$C$ trachomatis & $2 / 19(11)$ & $2 / 39(5)$ \\
Genital mycoplasmas & $11 / 42(26)$ & $31 / 47(66) \dagger$ \\
\hline
\end{tabular}

${ }^{*} \chi^{2}=5.41, \mathrm{p}<0.02$

$+\chi^{2}=12 \cdot 52, p<0 \cdot 001$

\section{Discussion}

This survey illustrates the complex aetiology of vaginal discharge among STD patients in Africa, in whom one quarter were infected with at least two genital pathogens.

The incidence of $N$ gonorrhoeae was much higher than that reported in antenatal and family planning clinic patients in other African countries where $2-12 \%$ of the women examined had gonorrhoea. ${ }^{1-4}$ The rate of isolation of $N$ gonorrhoeae was, however, only slightly higher than that among asymptomatic family planning clinic attenders in Nairobi in 1973 , when the prevalence was $19 \cdot 5 \% .{ }^{1}$ In a similar study in 1982 and using the same culture methods $17 \%$ of women attending a family planning clinic in Nairobi had gonorrhoea. ${ }^{14}$ Both family planning and STD clinic patients seemed to be an important reservoir of gonococcal infection in Nairobi.

In this series gonorrhoea was significantly associated with low abdominal pain. This suggests that PID was probably present. The simplest method of managing vaginal discharge would be for women with abdominal pain to be treated immediately for gonorrhoea, while the rest may be treated appropriately when the results of laboratory investigations are available. In most instances, however, no such facilities are available, and as the

TABLE I Micro-organisms isolated from patients with vaginal discharge in Nairobi by age group

\begin{tabular}{|c|c|c|c|c|c|c|}
\hline \multirow[b]{2}{*}{ Age (years) } & \multicolumn{6}{|c|}{ No of women harbouring: } \\
\hline & $\begin{array}{l}N \text { gonorrhoeae } \\
(n=122)\end{array}$ & $\begin{array}{l}T \text { vaginalis } \\
(n=I 22)\end{array}$ & $\begin{array}{l}\text { Calbicans } \\
(n=110)\end{array}$ & $\begin{array}{l}G \text { vaginalis } \\
(n=100\end{array}$ & $\begin{array}{l}\text { Genital mycoplasmas } \\
(n=89)\end{array}$ & $\begin{array}{l}\text { C trachomatis } \\
(n=58)\end{array}$ \\
\hline $\begin{array}{l}\leqslant 19 \\
20-29 \\
\geqslant 30\end{array}$ & $\begin{array}{r}13 / 98 \\
19 / 71 \\
0 / 13\end{array}$ & $\begin{array}{r}17 / 38 \\
21 / 71 \\
4 / 13\end{array}$ & $\begin{array}{r}7 / 34 \\
19 / 65 \\
0 / 11\end{array}$ & $\begin{array}{c}20 / 33 \\
50 / 60 \\
5 / 7\end{array}$ & $\begin{array}{c}12 / 28 \\
26 / 54 \\
4 / 7\end{array}$ & $\begin{array}{l}1 / 10 \\
2 / 40 \\
1 / 8\end{array}$ \\
\hline Total (\%) & $32(26)$ & $42(34)$ & $26(24)$ & $75(75)$ & $42(47)$ & $4(7)$ \\
\hline
\end{tabular}


overall prevalence of gonorrhoea is over $20 \%$ standard treatment for gonorrhoea should be given initially, as proposed by Meheus. ${ }^{15}$ The rationale for treating gonorrhoea first is to prevent the development of its debilitating complications primarily PID. If $C$ trachomatis proves to be as important a cause of these complications in Kenya as $N$ gonorrhoeae, these recommendations may have to be modified.

The cervical infection rate of $C$ trachomatis was lower than in STD clinic attenders in Europe and North America where chlamydiae may be isolated from the cervix of $12-31 \%$ of women seen in STD clinics. ${ }^{16}$ The prevalence of genital chlamydia infections was similar to that found in family planning and antenatal clinic patients in Nairobi, ${ }^{14}$ but was lower than among women with symptoms of genital tract infection in Gambia. ${ }^{17}$ The fairly low isolation rate of $C$ trachomatis contrasts with the high prevalence of gonorrhoea. We have found, however, that sera from $90 \%$ of various groups of women in Nairobi contained antichlamydial IgG antibodies indicating that chlamydial infections were extremely common in that population. ${ }^{14} \mathrm{~A}$ similar pattern of chlamydial infection has been found among black women in South Africa. ${ }^{18}$ Further research is needed on the role of genital chlamydial infections in such conditions as PID, infertility, and puerperal and perinatal morbidity in Kenya.

Trichomoniasis was the most frequent infection diagnosed. The incidence of this infection in the population studied is higher than that reported in studies of antenatal clinic attenders in Nigeria and in Swaziland ${ }^{24}$ and of family planning clinic attenders in Nairobi, where the respective figures were $20.7 \%$, $23 \cdot 3 \%$, and $25 \cdot 8 \%$. 1 A very high prevalence rate of $G$ vaginalis infection was found in this population, and that together with a high prevalence of other coexistent genital infections may have weakened any relationship between $G$ vaginalis and non-specific vaginitis.

\section{References}

1. Hopcraft M, Verhagen AR, Ngigi S, Haga ACA. Genital infections in developing countries: experience in a family planning clinic. Bull WHO 1973;48:581-6.

2. Osoba AO, Onifade A. Venereal diseases among pregnant women in Nigeria. W Afr Med $J$ 1973;22:23-5.

3. Widy-Wirski RR, D'Costa J. Prévalence des maladies transmises par voie sexuelle dans la population de femmes $\bar{\sigma}$ enceintes en milieu urbain en Centrafrique. In: Final report of $\overline{\bar{c}}$ the 13th Technical Conference, Yaounde, OCEAC, 1980:655-60.

4. Meheus A, Friedman F, van Dyck E, Gruyver T. Genital infections in prenatal and family planning attendants in $\infty$ Swaziland. East Afr Med J 1980;57:212-7.

5. Meheus AZ. Epidemiologie on bestrijding van geslachtsziekten $\vec{O}$ in Rwanda. Thesis, University of Antwerp, 1976.

6. Mati JKG, Anderson GE, Carty MJ, McGlashan HE. A $\vec{\omega}$ second look into the problem of primary infertility in Kenya. East Afr Med J 1973;50:94-7.

7. Carty MJ, Nzioki JM, Verhagen AR, McGlashan HE. The role $\stackrel{\mathscr{O}}{=}$ of gonococcus in acute pelvic inflammatory disease in Nairobi. OJ East Afr Med 1972; 49:376-9.

8. Walton SM, Mati JKG. An evaluation of secondary infertility in Kenya. East Afr Med J 1976; 53:310-4.

9. Totten PA, Amsel R, Hale J, Piot P, Holmes KK. Selective $\infty$ differential human blood bilayer media for isolation of $\mathrm{O}$ Gardnerella vaginalis. J Clin Microbiol 1982; 15: 141-7.

10. Ripa KT, Mårdh P-A. Cultivation of Chlamydia trachomatis in cycloheximide-treated McCoy cells. J Clin Microbiol 1977;6:328-31.

11. Braun $\mathbf{P}$, Klein JO, Kass EH. Susceptibility of genital mycoplasmas to antimicrobial agents. Appl Microbiol 1970; 19:62-70.

12. O'Callaghan C, Morris A, Kirby S, Shingler AM. Novel method for detection of beta-lactamase by using a . chromogenic cephalosporin. Antimicrob Agents Chemother 1972; 1:233-8.

13. Piot $P$, van Dyck E, Totten PA, Holmes KK. Identification of Gardnerella vaginalis. J Clin Microbiol 1982;15:19-24.

14. Nsanze H, Waigwa SRN, Mirza N, Plummer F, Roelants $P$, Piot $P$. Chlamydial infections in selected populations in Kenya. In: Mårdh P-A, Holmes KK, Oriel JD, Piot P, Schachter J, eds. Chlamydial infections. Amsterdam: Elsevier Biomedical Press, 1982:421-4.

15. Meheus AZ. Practical approaches in developing nations. In: Holmes KK, Mårdh P-A, Sparling PF, Wiesner PJ, eds. Sexually transmitted diseases. New York: McGraw Hill, (in press).

16. Oriel JD, Ridgway GL. Genital infection by Chlamydia trachomatis. London: E Arnold, 1982: 144.

17. Mabey DCW, Whittle HC. Genital and neonatal chlamydial infection in a trachoma endemic area. Lancet $1982 ; \mathrm{i}: 300-1$

18. Ballard RC, Fehler HG, Duncan MO, van der Wat IJ. Urethritis and associated infections in Johannesburg: the role $\delta$ of Chlamydia trachomatis. S Afr J Sex Transm Dis 1981;1:24-6. 